\title{
An empirical study on the effect of large scale computer assisted oral English test
}

\author{
TIAN Pinjing ${ }^{1, a}$ \\ ${ }^{1}$ Jilin Business and Technology College, Changchun 130000,China \\ aemail: tianpinjingjl@163.com
}

Keywords: Direct oral test; semi direct oral test; computer assisted oral test; Skype voice telephone

\begin{abstract}
The methods of quantitative and qualitative analysis, to Beijing Radio and Television University suburban districts and counties, 159 learners as subjects, using VoIP Skype distance under the condition of oral English test of empirical research to explore the new form of oral English test. Study found that: use Skype oral test can not only computer assisted oral English test to solve the problem of lack of interactivity and real, can effectively reduce the cost of management, balance the oral English test validity and reliability and is suitable for test of English majors new oral test form.
\end{abstract}

\section{Introduction}

The oral test is an important part of foreign language testing. With the deepening reform of College English teaching, foreign language testing theory research deeply and the growing needs of the community, the oral English teaching and testing has been paid more and more attention. How to provide scientific and efficient testing method of oral English teaching has become a hot topic in the domestic English education experts and scholars to study and explore. In the sustained and rapid development of computer technology today, to the greatest extent by students of computer network technology test of the true level of oral English and computer assisted oral English test to large-scale implementation and perfected from different perspectives[1], different levels, using different methods to explore new ways and methods of oral English test is very necessary.

Beijing Radio and Television University (hereinafter referred to as "Beijing Radio and TV University") to network teaching as the basis, in the city's 18 districts and part industry system has more than 50 basic teaching unit, which English professional enrollment each year about 400 people, distribution in Beijing Chengbaqu and suburban districts and counties of the campuses. In the past ten years, Beijing TV University uses the direct oral test, recording tape or CD as in the form of English Majors' oral test. In the process of implementing direct oral test, there are many problems in the course of implementation, which are difficult to evaluate, the resource of examiners and the cost of examination management.

In distance education and examination, based on computer and network technology in language testing has shown great advantages, on behalf of the future direction of development of our country college oral English test, and will gradually become a test of the mainstream. Therefore, School of large - scale, adopt a large number of modern educational technology for remote universities should explore new forms of Distance English oral test and implementation of remote condition of oral empirical research to test the in-depth exploration of the computer assisted oral English test form, validity, reliability and efficiency has important significance[2].

In the past ten years, the research content of the scholars in the oral English test mainly covers the following three aspects: 1) testing form, the topic and evaluation method research; 2) test the reliability and validity of; 3) to test the backwash effect of. Among them, the research on the methods and forms of oral test has become the focus of attention of domestic researchers. With the development of educational technology, the spoken English test has experienced three stages of development: direct, semi direct and computer assisted oral test. Direct oral test, referred to as OPI (interview oralproficiency), refers to the interviewer and the students face to face interviews, that is, the interview. College English four[3], six and IELTS (IELTS) oral test in the form of direct oral test. 
Semi direct oral sopi (oralproficiency interview simulated), usually refers to the oral test. Test the use of tape, CD or computer recording equipment to obtain the candidate's speech samples, by the examiner to listen to the recording and scoring. English majors four, eight, TOEFL (TOEFL) oral and self - Test - English is mostly used in this way. The network college and provincial TV University adopt both direct and semi direct oral test. Since the beginning of the new century, all the English Majors in Colleges and universities have begun to try to use the computer aided oral test, CALT (assisted LanguageTesting computer).

\section{Advantages and disadvantages of three types of oral test}

Domestic and foreign scholars from different perspectives on the pros and cons of various oral tests. Researchers believe that traditional direct oral proficiency test is close to the real life in oral communication activities, in the connotation also reflected the communicative function of language, examiners are directly involved in the real candidates of communicative activities directly observed examinee's facial expressions and body language, because this has "face validity, flexibility, according to the features of strong". However, the impact of factors such as the examiner resources, scoring criteria, "direct oral test scores reliability is generally low."

Domestic and foreign researchers have made a comparative study of direct and semi direct oral tests. Shohamy for direct and semi direct oral test analysis found that the two types of oral communication in the communication strategy and the characteristics of the discourse there is a big difference. In the semi direct oral test, students pay more attention to the correctness of language output, output of the discourse is more formal, rigorous, closer to the to the written expression; direct oral more make the examinee to melt in the discourse, than the language used in the semi direct oral more colloquial, candidates more attention to the interaction and the significance to convey, multi use the dialogical nature of language. Therefore, shohamy's conclusion is that the direct oral and semi direct oral tests are not completely interchangeable[4].

Jin Yan, Jack C. R through interview and semi direct recording oral contrast research that recording an interview with face to face interview is more economic and reasonable, and operability, can collect more samples of language, students oral English level of play from the examiner's language level and emotional impact, but it lacks the drawbacks of real communicative interaction are more prominent.

With the rapid development of the computer, the semi direct recording oral test has been gradually replaced by the computer assisted oral test. Cai Jigang by comparison of computer oral exam and interview examination results analysis, verify the computer-based oral proficiency test reliability and validity, it is pointed out that the computer-based oral proficiency test for the current needs of the community, the number of candidates, examination cost problem can be solved. Dong Lin Qiu in three large-scale computer-assisted oral English test practice based, and points out that the computer assisted oral English test, time saving, labor saving, convenient operation and easy, scoring relatively objective and fair, the test corpus for easy storage. In addition, many researchers in China have confirmed the advantages of computer assisted oral English test, but also found that the most important problem of computer aided oral test is the lack of authentic oral communication interaction. It can be seen that the computer assisted oral test is the development and extension of the semi direct oral test, so there are a lot of common points in its advantages and disadvantages.

"Based on the influence of linguistics, language teaching and psychological measurement, the task based language teaching and testing has become a hot research topic since the ninety's.." The oral English test by task type questions usually refers to "provide a certain mission scenarios, allowing candidates to use English to perform specific communicative tasks, the examiner by candidates of speech production and the completion of the task of judgment". However, the current problems in the computer assisted oral English test in our country can be summarized as follows:

Difficult to see from the above questions in design, reading, repetition, answer problem, talk about the pictures and verbal report questions require candidates communication is one-way, can not reflect the communicative authenticity and interactivity. Computer aided test has been found to be in leads to the discourse function and discourse range narrower than the direct oral problems, 
such as limited to the description of the report, and narrative language function, cannot be tested more advanced language skills. The limitations of the design of the test questions are mainly affected by the level of technical support. If the Committee debates and discussions on other questions in computer aided test environment is difficult. To give full play to the role of man-machine dialogue of a high-level language ability test, you need to get the support from the higher level of computer intelligence, "true intelligence, a test of spoken English software at present, it is very difficult to design, to research on computer aided adaptive spoken test system of corpus linguistics to invest more.

In view of the limitations of the above computer-assisted oral English test questions in the design of, at present computer assisted oral English test, the object of study is usually university English four, six level candidates. Reading and retelling, answer problem, talk about the pictures and other kinds of questions can basically reflect four, six levels of tests for non English Majors Oral inspection requirements, however, for English majors or upper intermediate level of English subjects, we usually have to through role play, group, discuss these forms in order to examine the test[5]

Oral communicative competence of students. It is because of these difficulties, the domestic English majors as the object of study of the long-range study of oral English testing can be described as is rare.

\section{The balance between reliability and validity: using Skype network voice telephone for direct oral test}

Reliability (reliabity) and validity (validity) are two important quality indexes for the evaluation of oral test. The consistency or stability of the examiner rating; validity ensures the validity and correctness of the test results. One of the characteristics of the development and evolution of the oral test form is that, in the premise of not giving up validity, the improvement of reliability is sought, and the balance between reliability and validity is obtained ".

How to integrate direct oral and computer aided test their respective advantages, both direct oral test with high validity, computer aided test reliability high, between the reliability and validity of reach relative balance by Skype voice telephone network pioneering significance in oral test.

Skype network voice telephone network telephone is the world's largest products, reputation in the telephone network, the total registered users more than 1 billion people. In the network voice chat function, Skype is a special communication software, the speech engine is superior to QQ and MSN, video than QQ clear, smooth, netizen "quality over the telephone" and "no need any complicated settings" highly, become by far the most popular, the international professional chat software.

In this study, think through the distance under the condition of new testing approaches, skyde VoIP -- direct English oral test for English majors to comprehensive direct and semi direct oral test advantage, both play a computer assisted oral English test management into the advantage of low, can solve the test interaction and authenticity, to achieve relative balance of oral test validity and reliability, and to address the development of the high cost of special software, and using two-way video to scale real brigade interview questions.

1) research objects and methods

The objects of this study are 159 students from the second grade at the outskirts of Beijing RTVU undergraduate english. This research adopts the method of qualitative and quantitative research, respectively for the teachers and students and technical staff conducted a questionnaire survey and interviews.

2) research questions and hypotheses

The research for candidates to learn to use the network speech telephone skvpe of oral tests, the new test form attitudes and reactions, mainly to answer three questions: (1) new oral testing whether can get students recognized? Test validity how? (2) new oral testing is not in emotion (particularly anxiety degree) influence the true level of the candidates play? The reliability test how? (3) new oral testing is feasible? 
To solve these problems, researchers make assumptions are as follows: (1) recognition using Skype VoIP calls of oral English test can be candidates, with high face validity; (2) using Skype VoIP calls for oral test, candidates can play a real spoken English level; (3) using Skype VoIP calls oral test is feasible.

Research on the design and implementation of 3

Beijing TV University Oral English test for academic examination (performance test), which is measured by learning difficulty degree of test depends on the difficulty of textbook. In the type of test questions, undergraduate English oral test by task type (Task-Based) test design, which provides a certain task and topic, require you to use English to complete specific communicative tasks. The ability of oral English test focused on candidates for expression and session on assigned topics related to the course.

In July 2009 and January 2010, 159 students from Yanqing TV University and Fangshan TV University participated in the research of Skype network speech software. According to the needs of large-scale English oral test, the use of the telephone network oral test in accordance with the "examination receive a piece. Examination arrangements exam published results of the four steps, simulates the traditional" face to face "dialogue for the oral examination. Interview the candidates enter the examination preparation, draw "ab test with a set of candidates, each selected papers for dialogue. Each paper includes two different session proposition (provide text prompts), the candidates were to start a topic. The oral exam, examiners teachers through the camera and microphone from candidates communication effectiveness, fluency, pronunciation, grammar and words in five aspects of the two candidates respectively on the spot comprehensive score.

\section{Research results and discussion}

The remote condition for oral test research using quantitative and qualitative analysis of the method to obtain the relevant data. Through the questionnaire of students, teachers and technicians, the researchers investigated the attitudes, reliability and validity of the students' oral test, and the validity of the test. The survey was carried out in January 2010, a total of 159 questionnaires, 142 valid questionnaires, the results are as follows:

1) surface validity

Validity is an important index in the theory of language testing, including the surface validity (validity face) and the content validity (contentvalidny). "Surface validity refers to the perceptions and attitudes of the candidates to the test." We used the questionnaire to understand the candidates to use the Skype interview satisfaction degree of data show that: the candidates for remote oral test of satisfaction as high as $81 \%$, not a student choice is not satisfied". Of course, there are $19 \%$ of the students on the remote conditions of the oral test, "the general feeling". Also survey candidates to participate in the distance under the condition of oral test of enthusiasm, we found, $88 \%$ of the students willing to actively participate in the remote oral examination, $8 \%$ of the students was noncommittal, only $4 \%$ of the students held a negative attitude.

These data prove that the first hypothesis of this study: the use of the Skype VoIP calls of remote oral test overall by the candidates generally recognized, most students to a positive attitude, that is, the remote oral test has satisfactory face validity.

2) the authenticity of language output

A large number of studies show that in recording oral test and ordinary computer assisted oral exam, candidates in front of a tape recorder or computer speech, it's hard to find a real feeling, candidates are "unnatural" "one-way communication in the imaginary audience or dialogue". Compared with the traditional test, we found that $41 \%$ of the students think that their in the distance under the condition of the oral exam content and expression of "richer", $48 \%$ of the students think their own play normal, with normal examination amounts: $11 \%$ of students feel poor play. The survey data indicate that increase in camera after the examinee and examiner also on the computer screen to see each other, because dual visual and auditory stimulation and closer to the real communicative and improve the interactive computer-based oral proficiency test and authenticity, help to students' language output, objective, reflect the students' oral English level. 


\section{3) content validity}

"Content validity refers to whether the project and task in the test is consistent with the overall goal of the test." Testing is only able to accurately measure the content of what it wants to be tested. Researchers asked candidates on their overall performance for self evaluation. The results showed that: compared with the traditional test, $54 \%$ of the students think the distance under the condition of oral test, their performance is more satisfactory, $40 \%$ of the students think network environment their English level test and traditional test not too big difference, can play a normal. Beijing TV is a test of spoken English for academic examination, test questions difficulty depends on difficulty of textbook, examination of oral communicative task and test the overall target is basically consistent, so candidates are more familiar with test content, can play their normal level during the interview and performance of their own satisfaction. Therefore, the above data analysis part of the proof of the second assumption of this study: use Skype VoIP calls for oral English achievement test, candidates can play a real spoken English level, at the same time, the task-based oral English test has a high content validity.

4) degree of anxiety

In the testing process, the examinee can give full play to the true level to a large extent by the influence of the emotional state. The traditional interview, the interviewer's attitude is conducive to ease the tension of the candidates, and the examiner's attitude will increase the students' anxiety, the impact of the level of play. Distance under the condition of oral test environment, in the absence of the examiner directly involved in oral communication of the anxiety level of candidates is reduced? According to the survey, $59 \%$ of the students feel at a distance facing the examiner case "more relaxed"; 31\% of the students think oral English under the network environment

Examination of the psychological "more nervous". This shows that in the long distance oral test, the examinee to face the new test means inner anxiety is inevitable. Because of the oral test examiners teachers did not participate in the discussion of students. Candidates do not directly face the examiners test, on the one hand can make the examinee psychological tension in a large extent eased, can play a normal; on the other hand, the examiner can avoid being students appearance, dress and behavior influence subjective judgment, the realization of the evaluation of fairness, to avoid face-to-face direct test reliability relatively low drawbacks. Therefore, the data also proved that the study of the second hypotheses: the use of Skype network voice telephone test, candidates can play to the true level, and to reduce their anxiety.

5) the operability of examination management

How to operate the remote oral test? This question involves the examination organization implementation, the examiner score resources, the site equipment, the examination time and so on the cost factor. That is to say, in ensuring the same reliability and validity of the premise, the shorter the test time, the less the use of the examiner or less, the less the use of the site and equipment, the lower the cost, the stronger the operability. For the examination of the organizational form, students generally have more positive attitude, $57 \%$ of the students think distance under the condition of oral exam organization "more flexible", 33\% of the candidates think examination more "save time".

\section{Conclusion}

The application of computer technology in other fields has greatly improved the working efficiency of the field. The use of Skype network voice software in the remote condition is the application of computer network technology in the field of foreign language testing, it has a new exploration of the form of foreign language testing in the form of remote conditions. The study shows that compared with the direct and semi direct oral test, the oral testing long-range can not only effectively reduce the cost of management, also show examinee dialogue interaction and authenticity, lower the degree of the examinee of anxiety, improve the test reliability and validity, to justice and effectively test the examinee's oral English ability is an effective method suitable for learners of English in senior level test. 


\section{References}

[1] Zou Shen. A discussion on the authenticity of the spoken language test [j] foreign language world, 2001,0):74-78.

[2] Li Yuping. An Empirical Study on the effect of large-scale computer assisted oral English test [j] foreign language sessions, 2009, (4):69-76.

[3] Jin Yan, Guo Jack. The validity of the and six oral test in College English and four [j] foreign language circle, 2002, (5):72-79.Shohamy e., the validity of direct versus semi-direct.

[4] oraltests [j]. language testing, 1994, (11): 99-123.

[5] Cai Jigang. The validity, reliability and operability of the four and six computer oral test in College English [j], 2005, (4):66-75. 